\title{
Synthesis and Manufacturing of Sustainable Hybrid Composites using Sisal and Hemp fibres as Reinforcement in Poly (lactic acid) via Injection Moulding
}

\author{
Asokan Pappu ${ }^{1 *}$, Kim L Pickering ${ }^{2 *}$ and Vijay Kumar Thakur ${ }^{3 *}$ \\ ${ }^{1}$ CSIR- Advanced Materials and Processes Research Institute, Bhopal, India \\ ${ }^{2}$ School of Engineering, University of Waikato, Hamilton, New Zealand \\ ${ }^{3}$ Enhanced Composites and Structures Center, School of Aerospace, Transport and \\ Manufacturing, Cranfield University, Bedfordshire MK43 0AL, UK \\ Email ID: asokanp3@yahoo.co.in ; KLP@waikato.ac.nz; Vijay.Kumar@cranfield.ac.uk
}




\begin{abstract}
Sustainable biodegradable polymer composites offers significant advantages over synthetic fibre reinforced petroleum matrix based composites with regard to biodegradability, biocompatibility, design flexibility and sustainability. On the other hand, natural fibre composites are lighter in weight and can provide energy and cost savings. In the present study, granulated sisal and hemp fibres were blended and hybrid "green” composites were manufactured using aliphatic polyester made up of lactic acid (PLA) through extrusion and injection moulding and their performance was evaluated. Experimental results revealed that density, elongation at break and water absorption capacity of hybrid composites were $1.14 \pm 0.075 \mathrm{~g} / \mathrm{cm}^{3}, 0.93 \pm 0.35 \%$ and $1.06 \pm 0.18 \%$ respectively. The achieved mean tensile strength (46.25 $\pm 6.75 \mathrm{MPa})$, Young's modulus (6.1 $\pm 0.58 \mathrm{GPa})$ and specific tensile strength (38.86 \pm 5 ) of hybrid fibre reinforced PLA composites were improved compared to neat PLA. The flexural strength $(94.83 \pm 11.21 \mathrm{MPa})$, flexural modulus (6.04 $\pm 0.55 \mathrm{GPa})$ and specific flexural strength (79.76 \pm 8.8) of hybrid fibre composites also showed better performance than those of neat PLA. Incorporation of sisal and hemp fibre with polylactide remarkably increased the impact strength of composites. Addition of hybrid natural fibre seems to have influenced melt viscosity, leading to decreased crystallinity and induced strain hardening. Overall, green hybrid composites had good performance suggesting that they have considerable scope for use as an environmentally friendly alternative material in automotive, packaging, electronics, interiors and agricultural applications.
\end{abstract}

Keywords: Sisal fibre; Hemp fibre; Poly(lactic acid); Biodegradable hybrid composites; Extrusion; Injection moulding; Thermal degradation; Mechanical properties

\title{
1. Introduction
}

There is an enormous variety of natural fibres including flax, grewia optiva, hibiscus sabdariffa, jute, hemp, coir, Saccharum cilliare, ramie, sisal, banana, pine needles and pineapple to name a few which mainly consist of cellulose, hemicelluloses and lignin (Bleuze et al., 2018; de Oliveira et al., 2017; Goudenhooft et al., 2018; Kaschuk and Frollini, 2018). The physico-chemical and mechanical characteristics of these natural fibres 
are generally found to be dependent on the source and age of plants as well as cellulose content and are influenced by alkali treatment which removes hemicelluloses, lignin and other impurities including wax from the fibre (Requile et al., 2018) (Pappu et al., 2015; Singha et al., 2008). Natural fibres are used as replacement for glass fibre in composites attributed to their enormous advantages such as low density and environmental friendliness in terms of low energy consumption and renewability(Ochoa et al., 2017; Singha and Kumar Thakur, 2008; Thakur et al., 2012). However, compared to glass fibre they have lower heterogeneity, poor crimp properties which hamper yarn making, more limited processing temperatures as well as being hydrophilic and thus inherently incompatible with many matrix materials(Pappu and Thakur, 2017; Singha and Thakur, 2009; Thakur and Singha, 2010). In the present study, granulated hemp fibre and sisal fibre were used in making hybrid green composites with polylactic acid. These fibres have relatively high fibre strength and long fibre when compared with other natural fibres(Pappu et al., 2016). In this article, we report on the properties of biodegradable green composites fabricated using extrusion and injection moulding.

\subsection{Hemp Fibre}

Hemp (Cannabis sativa6 L.) is a plant in the Cannabaceae family which has been used historically as a source of fibre. The cultivation propagation of hemp for fibre production is mostly done through seedlings. There are two types of hemp fibre, namely (i) industrial hemp fibre, derived from the bast material and (ii) Manila hemp fibre, derived from the leaves(Liu et al., 2017). Harvesting of hemp plant normally takes place four to five months after sowing. The height of the final hemp plant is usually about $2 \mathrm{~m}$ with a $0.5 \mathrm{~cm}$ diameter. Usually, hemp plants (stems) are cut 2-3 cm above the soil surface and spread on the ground to dry before the fibre is extracted by retting. However, fibre can also extracted from green stems before drying of harvested plants. According to the climatic conditions and available local facilities, hemp can be water retted, dew retted, or snow retted(Liu et al., 2017). The retted hemp stalks consist of fibre in the outer peel and brushwood in the interior portion and the fibre is separated from the stalk either manually or mechanically. Mechanical separation of the outer peel and brushwood fibre is commonly carried out by scotching involving passing stalks through a number of fluted rollers. It is estimated that the yield of 
dried hemp fibre is about $25 \%$ of the weight of the dried hemp straw. However, the fibre yield depends on plant height; the taller the plant, the greater the fibre yield. Russia is the largest producer of hemp fibre in the world accounting for about $33 \%$ of the annual world production of 255,000 tonnes. Other countries such as France, Germany, Italy, Yugoslavia, Chile, China, Japan and Peru also produce considerable quantities of hemp fibre. However, India is the main producer and exporter of oil from hemp seed(Bodros et al., 2007). It is reported that hemp stem yields of more than $10 \mathrm{t} / \mathrm{ha}$ can be achieved dependent on the hemp variety and growing climatic conditions. Hemp plant tends to exhaust soil nutrients; however, medium fertility soil is the most desirable for cultivation of hemp plant.

The chemical properties of hemp fibre have been studied by several researchers and the major chemical compositions in hemp fibre are: cellulose (55-75 \%), hemicellulose (10-24 \%), lignin (4-13\%) and wax (0.7-3\%)(Pickering et al., 2016). Hemp fibre has been reported to have a tensile strength of 514-690 MPa and Young Modulus of about 24-60 GPa(Liu et al., 2017; Pappu and Thakur, 2017). Hemp fibre has been used traditionally for making rope and found to be a potential reinforcing fibre in polymer matrix composites for value added applications.

\subsection{Sisal Fibre}

Sisal belongs to the Agave family and Agave sisalana is the prominent variety, commonly available in most countries and also being cultivated with minimum financial input and maintenance Sisal fibre exhibits relatively high mechanical properties in comparison to other natural fibres such as coir, jute, cotton, palm, and bamboo(Pappu et al., 2016; Senthilkumar et al., 2018). Sisal leaves are on average about $1.5 \mathrm{~m}$ in height, $7.5 \mathrm{~cm}$ wide at the base, $12 \mathrm{~cm}$ wide at the middle portion, ending with sharp tip. Sisal leave harvesting usually starts after three years. Normally a sisal plant yields about 200 leaves within a life span of about 7 years. Also, mature sisal plants yields shoots from stolons called bulbils which are traditionally used for further propagation.

Annually, about 4.5 million tonnes of sisal fibres are produced globally and Tanzania, Brazil, China, South Africa are major sisal fibre producing countries(Pappu et al., 2015). Traditionally, sisal fibre is extracted using retting, chemical treatment and mechanical extraction. Presently, mechanical extraction of sisal fibre is done using an indigenous 
machine known as Raspador machine. Sisal fibre consists about 55-78\% cellulose, 8-19\% hemicellulose and 2-11\% lignin, about 1\% pectin with 6-10\% moisture content(Pappu et al., 2016). Sisal fibre is traditionally used for making ropes, cards, fishing nets, padding mat, ropes for the marine industry as well as decorative articles including table mats, purses and wall hangings. It is an emerging reinforcing material for use in polymer composites for several industrial engineering applications. Sisal fibre has a diameter of around $200 \mu \mathrm{m}$, tensile strength about 600MPa, Young's modulus approximately 15 GPa with elongation about $5 \%$.

\subsection{Fibre Composites}

A composite material is made up of two or more than two different constituents wherein one or more of the constituents is dispersed in another constituent called a matrix. They can and can be classified as polymer matrix composites (PMCs), metal matrix composites (MMCs), and ceramic (including concrete, clay and cement) matrix composites (CMCs). MMCs are strong and exhibit intermediate stiffness; PMCs are low in density with strength and stiffness fibre dependent; CMCs are brittle, stiff and high temperature resistant; cement and concrete composites exhibit high strength and stiffness. The reinforcement for these composites can be either fibrous or particulate. In PMCs natural fibres have been explored due to their potential to produce eco-friendly, cost-effective, low density alternatives to glass fibre reinforced plastics.

Generally, fibre reinforced polymer composites have shown better properties in terms of their strength, stiffness, low density than other composites. Moreover, they can provide better energy savings and are more environmentally friendly than MMCs and CMCs. In polymer matrix composites, the most commonly used thermoset polymers are: polyester, phenolics, epoxy; thermoplastic polymer matrices include: polypropylene, polyethylene, polystyrene. It is recorded that natural fibre-based thermoset composites result better mechanical properties than for thermoplastic composites, but thermoplastic composites have advantage for design flexibility and recycling potential. The fibre used in polymer composites is broadly classified as synthetic fibre (glass, aramid, carbon, etc.) and natural fibre (jute, hemp, flex, sisal etc.). Currently bio-plastics are becoming increasingly attractive polymers for different industrial applications due to various environmental 
threats as replacement for traditionally used synthetic polymers such as polyester, polyurethane and phenolic resins(Zhang et al., 2018b, 2018a) .

\subsection{Biodegradable Polymers for Composite Matrices}

Many different polymers have been developed from renewable resources and have potential as composite matrices, but their low toughness, easy commercial availability, processability, high cost, low moisture resistance and thermal stability are some of major concern. Considerable research has been conducted on the use of biopolymers such as acetic acid, polylactic acid (PLA), modified cellulose, soya oil based epoxy, polycaprolactone (PCL), polyhydroxybutyrate (PHB), lignin and starch(Dubey et al., 2017; Miculescu et al., 2017) . PLA is based on copolymers of poly (D-L-lactic acid) (PDLLA) and poly (L-lactic acid) PLLA) produced from D-lactides and L-lactides respectively and is completely biodegradable. Degradation of PLA mainly occurs over a two week span during composting with agricultural residues and with full decomposition within a period of about four weeks due to hydrolysis to acidic acid under microorganism activity to water and CO(Gan and Chow, 2018; Panaitescu et al., 2016). In comparison, aromatic polyesters, polyurethanes, polyamides are hardly susceptible to microbial attack and are not biodegradable.

\subsection{Natural Fibre Composites}

Increased consciousness of global climate change has attracted researchers' and technocrats' attention to the use of natural cellulose fibres for a number of applications. Though natural fibre based composites exhibit lower strength and stiffness than synthetic fibre reinforced composites, use of natural fibres has considerable benefits relating to cost effectiveness and the environment. Moreover, these composite materials exhibit good sound absorption, reduced weight and enhanced fuel efficiency in automotive applications. It is evident from earlier work that the presence of lignin and hemicelluloses in the natural fibre negatively influences the durability of the natural fibre composites. The major constraints associated with natural fibres in composites are moisture sensitivity due to their hydrophobic nature, limited processing temperature, poor inherent interfacial adhesion between fibre and polymer matrix and variability in fibre characteristics(Thakur and 
Singha, 2010). Natural fibre composites do not accomplish the equivalent strength as glass fibre composites exhibit. However, it is reported that specific properties of natural fibre reinforced composites are as good as those of the glass fibre reinforced thermoplastics(Thakur and Thakur, 2014). Much research has been carried out by researchers and considerable improvement on interfacial bonding between fibre and matrix through modification of matrix hydrophobicity and fibre surface treatments has resulted(Thakur et al., 2014). The demand for natural fibres in PMCs is substantially increasing in Europe, North America and other developing countries and has great scope to substantiate in meeting the future challenges on biomaterials.

Amongst all natural fibre composites, those containing sisal exhibit the highest impact strength besides moderate tensile and flexural strength(Sarasini and Fiore, 2018). However, hemp fibre exhibits better tensile strength and proves to be a good reinforcement in various polymer matrices(Liu et al., 2017; Saradava et al., 2016).

Natural fibre reinforced biodegradable polymer composites exhibit many advantages as compared to synthetic fibre reinforced petroleum product based composites, however, it is reported that they still have limitations regarding mechanical properties(Saradava et al., 2016). To attain better mechanical properties, appropriate treatment and modifications in natural fibers are carried out using biodegradable resins and considerable improvement has been recorded with the composites developed found to be biodegradable and sustainable. Though, so far, polylactic acid (PLA) has only been used in biomedical applications, the discovery of a new polymerisation technique has resulted in cost-effective production of polylactic acid (PLA), supporting its use for consumer products and packaging materials (Dubey et al., 2017). In hybrid fibre composites, although several types of fibre can be used in the same matrix, a combination of two types of fibres has been found to be the most desirable to enable a balanced performance of properties. Natural fibre based thermoplastic composites can be made through compression molding, extrusion, pultrusion, injection molding. However, no work has been reported yet on hybrid fibre reinforced biodegradable composites using sisal and hemp fibre with polylactic acid using melt processing and injection moulding.

In the present study, equal parts of micronized sisal and hemp fibres were blended homogeneously and hybrid green composites were made using polylactic acid (PLA) 
through extrusion and injection moulding and assessed regarding their physical, mechanical thermal and crystallinity characteristics. This paper describes a process to synthesise and manufacturing of hybrid natural fibre (sisal-hemp fibre) poly-lactic acid composites and their characteristics for possible use as an auto component and as interiors/architectural materials in automotive and construction industries (Scheme 1).

\section{Methodologies}

\subsection{Raw Materials: Natural Fibre and Polylactic Acid}

Hemp fibre was obtained from Hemcore, UK and sisal fibre was brought from CSIRAMPRI, Bhopal, India (Figure 1). Commercial grade polylactic acid (PLA) 4042D was obtained from Nature Works LLC, USA was used. The density of the PLA was 1.25 g/cc. PLA exhibits good mechanical, physical and barrier properties as compared to commercial petroleum based polymer.

\subsection{Fibre Processing}

Sisal fibre was dried at $80 \pm 2^{\circ} \mathrm{C}$ for $24 \mathrm{hrs}$. Hemp fibre was soaked in hot water $\left(85 \pm 2^{\circ}\right.$ C) for 10 minutes and cleaned and unwanted impurities were removed manually (Figure 1). The cleaned wet hemp fibres were oven dried at $80 \pm 2^{\circ} \mathrm{C}$ for 12 hrs. The dried hemp and sisal fibre were aligned as a mat using a hand carding machine during which any further unwanted impurities in the stack of fibre were removed (Figure 1).

\subsection{Preparation of Hybrid Fibre}

The cleaned and carded fibres (Figure 2A-B) were cut into at $4 \mathrm{~mm}$ lengths using a granulator with a tri-blade cutting system, designed especially for natural fibre. For composite fabrication, PLA pellets were ground into powder (Figure 2C) using a microniser (Model 15 A, Eriez manufacturing Co. Erie PA, USA). Granulated sisal and hemp fibre were mixed homogenously in a 1:1 ratio (Figure 2D) and oven dried at $80 \pm 2^{\circ}$ C for 12 hrs prior to composite synthesis. 


\subsection{Synthesis and Manufacturing of Composites}

Initial formulation of the composites prepared is described in Appendix-1. It is known from several reported works that incorporation of natural fibre from 25-35 wt\% in polymer composites is found to be the most appropriate to achieve optimum technical and economic benefits and addition of more than $30 \mathrm{wt} \%$ fibre has not resulted in any significant enhancement in the mechanical properties of PLA fibre composites(Islam et al., 2010). Hence, in the present study, attempts were made to use $30 \mathrm{wt} \%$ natural fibre with PLA using optimised conditions. Compounds were prepared using $15 \mathrm{wt} \%$ each of oven dried and granulated sisal and hemp fibre (1:1 ratio) with $70 \mathrm{wt} \%$ polylactic acid in a twin screw extruder (Thermo Prism). The operating condition of the extruder was $175^{\circ} \mathrm{C}$ at the feeding zone; $190{ }^{\circ} \mathrm{C}$ in the mixing zone; $190{ }^{\circ} \mathrm{C}$ in the reacting zone, and $180{ }^{\circ} \mathrm{C}$ at the die exit. In the extrusion process a 75 rpm ram speed and 28-32 \% torque was maintained. Extruded compound was granulated to a size of $4 \mathrm{~mm}$ using granulator. Figure 3 (A) and 3(B) shows the extruded and granulated compound respectively. Composite specimens were made in an injection moulding machine and the operating temperature was $160{ }^{\circ} \mathrm{C}$ at the feeding zone; $180{ }^{\circ} \mathrm{C}$ at mixing zone; $190{ }^{\circ} \mathrm{C}$ at the reacting zone and $200{ }^{\circ} \mathrm{C}$ at the die exit zone and maintaining a ram pressure of $30 \mathrm{kN}$. For comparison, micronized PLA was oven dried and injection moulded to obtain test specimens under the above conditions. Injection moulded tensile specimens are shown in Figure 3 (C, D).

\subsection{Materials Characterisation}

\subsubsection{Fibre Diameter and Strength Measurement}

Fibre diameters of both hemp and sisal were measured employing an optical microscope (Olympus BX 60) at X10 magnification in a horizontal direction. For measuring fibre diameter, processed sisal and hemp fibres were cut into $25 \mathrm{~mm}$ length and fixed to a cardboard window frame as described in ASTM C 1557-03 (Standard Test Method for 
Tensile Strength and Young's Modulus of Fibres). Further, tensile testing was performed compliance with the above standard. Twenty five samples were tested for each fibre type.

\subsubsection{Tensile Testing of Composites / PLA}

Tensile testing of injection moulded composite/PLA specimens was performed in compliance with ASTM D 638-03 (Standard Test Method for Tensile Properties of Plastics). Samples were analysed using an Instron tensile testing machine (Instron 4042) using a $5 \mathrm{KN}$ load cell and a $50 \mathrm{~mm}$ gauge length with $0.5 \mathrm{~mm} / \mathrm{min}$ cross-head speed. Five hybrid composite specimens were tested to check the reproducibility of the results.

\subsubsection{Flexural Testing of Composites}

For flexural testing, injection moulded rectangular-type specimens were used. Three point bending was performed to comply with ASTM D 790-03, applicable for testing reinforced and un-reinforced plastics, using a Lloyd $100 \mathrm{KN}$ machine with a $5 \mathrm{KN}$ load cell with a span of $60 \mathrm{~mm}$ and a cross-head speed of $1.5 \mathrm{~mm} / \mathrm{min}$.

\subsubsection{Impact Strength Testing of Composites}

For impact testing, injection moulded rectangular specimens were cut into a specimen size of 80x8x3.5 mm (Figure 3 (E, F)) using a laser cutting machine. The Charpy impact test was performed on the hybrid composites as per the method prescribed in the International Standard Organisation (ISO 179-1:2000) for determination of Charpy Impact Properties of

Plastics using a Polytest impact tester with a universal pendulum with a hammer weight $0.475 \mathrm{~kg}$ at an impact velocity of $2.9 \mathrm{~m} / \mathrm{s}$ at $21^{\circ} \mathrm{C}$ wherein test specimen rested over two supports on either side of the test notch. Six replicate specimens were tested to confirm the reproducibility of the results.

\subsubsection{Thermal Analysis of Composites}

Thermal analysis was performed using a differential scanning calorimeter (DSC 2920) to assess the thermal stability of hybrid fibre reinforced PLA composites. In addition, thermal 
gravimetric analysis and differential thermal analysis was carried out employing a simultaneous DTA-TGA (SDT 2960) analyser. A heating rate of $5^{\circ} \mathrm{C} / \mathrm{min}$ was applied for both techniques from room temperature to a maximum temperature of $600^{\circ} \mathrm{C}$ with a static air flow of $150 \mathrm{ml} / \mathrm{min}$. A hybrid composite sample size of approximately $10 \mathrm{mg}$ of sample was used for both tests.

\subsubsection{Dynamic Mechanical Analysis of Composites}

The mechanical response of hybrid composites was tested using a Perkin Elmer DMA 8000 , to monitor the effect of frequency, temperature and time under an oscillating force where in the sinusoidal stress/ strain curves were recorded as a function of time. Hybrid composite specimens of dimensions $30 \mathrm{~mm} \times 7.08 \mathrm{~mm}$ x $3.64 \mathrm{~mm}$ with a free length of 12.5 $\mathrm{mm}$ (Fig.10) were scanned at frequencies of 1,10 and $30 \mathrm{~Hz}$ with $0.5 \mathrm{~mm}$ dynamic displacement at a temperature ramp rate of $2^{\circ} \mathrm{C}$ per minute from room temperature to $120^{\circ}$ $\mathrm{C}$ under single cantilever bending. Parameters obtained were: (i) storage modulus ( $\mathrm{E}^{\prime}$ ) (ii) loss modulus ( $\left.\mathrm{E}^{/ /}\right)$and (iii) the mechanical damping factor $(\tan \delta)$.

\subsubsection{XRD Analysis and SEM Microstructure of Composites}

XRD analysis was performed between a $2 \theta$ angles of 12 to $45^{\circ}$ at a scanning speed $0.02^{\circ}$ \% second to study cellulose crystallinity. Composite fracture surfaces were analysed employing a scanning electron microscope (Hitachi S 4700) under operating condition of $10 \mathrm{kV}$.

\subsubsection{Density and Water Absorption Studies of Composites}

The density of a material can be influenced by its crystallinity, absorption capacity and environment. Density of hybrid natural fibre PLA composites was determined using a high precision micro balance as prescribed in ASTM D 792-08 (Density and Specific Gravity of Plastics by Displacement). Samples stored in air and immersed in water were studied. Water immersion was studied as per ASTM D 570-98 (Standard Test Method for Water Absorption of Plastics). Initially these were dried until a constant weight was attained. Then, each sample was submerged in distilled water separately at $20 \pm 2^{\circ} \mathrm{C}$ for 24 hours 
during which they were taken out periodically and subsequently weighed, after wiping the water from the specimen surface. The percentage water absorption was calculated from the weight of the hybrid composite specimens prior to and after immersion in water.

\section{Results and Discussions}

\subsection{Characteristics of Sisal and Hemp Fibre}

The unprocessed sisal fibre was observed to be white and bright in colour in contrast to hemp fibre which is brown. Figure 4 shows the microscopic view of (A) sisal fibre and (B) hemp fibre. The average diameter of single sisal and hemp fibres was found to be $268.79 \pm 77.89 .1 \mu \mathrm{m}$ and $105.08 \pm 48.84 \mu \mathrm{m}$ respectively. Density of hemp fibre was found to be $1.48 \mathrm{~g} / \mathrm{cm}^{3}$ whereas the density of sisal fibre was recorded as $1.42 \mathrm{~g} / \mathrm{cm}^{3}$. The average tensile strength of sisal fibre was $294 \pm 113.2 \mathrm{MPa}$ and hemp fibre was $423 \pm 186 \mathrm{MPa}$. The tensile modulus of sisal fibre was $9.77 \pm 0.88 \mathrm{GPa}$ which was less than that for the hemp fibre (14 $\pm 3.8 \mathrm{GPa})$. Work carried out by several researchers has shown that the tensile strength of untreated sisal fibres mostly varied from $340 \mathrm{MPa}$ to $700 \mathrm{MPa}$ and tensile modulus 12.8 to $20 \mathrm{GPa}$. Overall, compared to sisal fibre, the tensile strength/ tensile modulus of hemp fibre was found to be higher.

\subsection{Characteristics of Hybrid Composites}

The physical and mechanical properties of hybrid natural fibre reinforced green PLA composites and neat PLA are shown in Table 1 and Table 2 respectively.

\subsection{Tensile Testing of Composites}

Tensile strength of hybrid composite specimens developed using sisal-hemp fibre reinforced with polylactic acid under extrusion and injection moulding varied from $40 \mathrm{MPa}$ to $59 \mathrm{MPa}$ with an average strength of $46 \mathrm{MPa}$. Figures 5 (A) and (B) show the stress 
versus strain graphs for PLA and hybrid fibre reinforced composites respectively. PLA showed a tensile strength of $35 \mathrm{MPa}$ and a modulus of $3.5 \mathrm{GPa}$ (Table 1). Addition of sisal and hemp fibre contributed to an increase in tensile strength of composites about $20 \%$. The tensile modulus of hybrid fibre reinforced PLA composites was $6.1 \pm 0.58 \mathrm{GPa}$ which was 42.9\% higher in comparison to the pristine PLA.

It is worthy to note here that composites with a polypropylene matrix used currently in automotive applications exhibit tensile strength/ modulus of $28 \mathrm{MPa}$ and 1.3GPa respectively(Islam et al., 2010). The present study demonstrates fully biodegradable composites without compromising its quality as a viable option for automotive applications. Decrease in tensile performance of hybrid fibre composites was observed to occur when test specimens failed near the grips(Saxena et al., 2008). Recent work in the literature reports bio composites made using PLA reinforced with 25\% flax fibre to have a specific Young's modulus of $6.5 \mathrm{GPa}$ which was close to that achieved with glass polyester composites (7.8 GPa)(Saxena et al., 2008).

The specific tensile strength of hybrid fibre reinforced PLA composite was 38 which is about 22\% higher than that for neat PLA. The interface among the matrix and fibre is very important for load transfer and therefore load bearing. The properties of natural fibre reinforced PLA composite depends upon on fibre length/orientation, matrix properties (kinetics and crystallinity) and processing techniques. Roughness of fibre surfaces assists mechanical interlocking with matrices. Hemp fibre here was found to be have a rougher surface than the sisal fibre and so could be expected to have better interfacial bonding with the matrix. It is reported that exposed cellulose hydroxyl groups can lead to covalent and hydrogen bonding with matrices which enhances mechanical properties and thermal stability. Cellulosic fibres are rigid and brittle and hence they act as stress concentrators, leading to reduction in the ultimate elongation of hybrid composites. The stress-strain curves of hybrid fibre composite are shown in Figure 5. The tensile fracture of hybrid fibre composite shows linear deformation at lower strains and nonlinear deformation at higher strains with lower failure strains generally than for PLA alone. 


\subsection{Flexural Testing of Composites}

The graphs of flexural stress versus flexural extension obtained during three point bending of PLA and hybrid fibre composites are shown in Figure $6(\mathbf{a}, \mathbf{b})$ respectively. The average flexural strength of neat PLA was $82 \mathrm{MPa}$ with a flexural modulus of $3.2 \mathrm{GPa}$. However, the flexural strength of polylactic acid reinforced with hemp and sisal fibre ranged from approximately $81 \mathrm{MPa}$ to 104MPa with flexural modulus of $6 \mathrm{GPa}$. The specific flexural strength of hybrid fibre reinforced PLA composites was 79 which is about $27 \%$ higher than that for PLA specimens without reinforcement. It is observed from the present study that sisal and hemp fibre incorporation resulted significant enhancement in tensile and flexural properties followed by an excellent aroma and better heat stability. Hybrid fibre contributed to the increment in the tensile and flexural modulus of composites. Tensile and flexural modulus of composites with cellulose fibre incorporation were found to exhibit mutually exclusive properties and the flexural strength values are consistent with tensile strength where in flexural strength found to be proportionately increased the flexural modulus.

\subsection{Impact Strength of Composites}

The charpy impact test of the hybrid composite specimens was performed with universal pendulum at an impact velocity of $2.9 \mathrm{~m} / \mathrm{s}$ wherein test specimen rests over two supports on either side of the test notch. Result revealed that the impact strength of hybrid composite developed using sisal-hemp fibre reinforced with polylactic acid varied from $9.21 \mathrm{KJ} / \mathrm{m}^{2}$ to $11.08 \mathrm{KJ} / \mathrm{m}^{2}$ (Table 1). It is apparent that impact strength is expressed to measure the ability of materials to withstand fracture. Neat PLA exhibits low impact strength $(6.4 \mathrm{KJ} /$ $\mathrm{m}^{2}$ ) and was brittle in nature however, the present study revealed that incorporation of sisal and hemp fibre with polylactide remarkably increased the impact strength Pappu et al., 2016 reported that bi-directional sisal textile fibre reinforced polyester composites $(0.4$ volume fraction) exhibited impact strength of 21.803+1.84 KJ/m2(Pappu et al., 2016) . It is evident from all these studies that fibre incorporation enhances the impact strength of

PLA composites. In the present study, extruded and injection moulded hybrid natural fibre composites might have reduced the aspect ratio of biofibers and thus improved fibre matrix adhesion better than long fibre leading to improved mechanical properties. This has been 
substantiated with the results of percentage elongation at break and possibly the reduction in toughness as could be recorded from the area under the stress-stain curve.

\subsection{Thermal Analysis of Composites}

\subsubsection{Dynamic Mechanical Analysis of Composites}

Result of properties from dynamic analysis for PLA and hybrid composites are shown in Figure 7. The changes in (a) storage modulus ( $\left.E^{\prime}\right)$, (b) loss modulus ( $\left.E^{/ /}\right)$and (c) mechanical damping factor ( $\tan \delta$ ) shows that there are significant changes relating to the degree of molecular mobility in hybrid natural fibre PLA composites. $E^{\prime} / E^{\prime \prime}$ was found to be higher for composites than PLA across the entire spectrum of temperature studied. The glass transition temperature (Tg) increased from $50^{\circ} \mathrm{C}$ for PLA to $80^{\circ} \mathrm{C}$ for composites. After a big drop in $\mathrm{E}^{\prime}$ associated with Tg, it was found that increase again to give a small peak at $80^{\circ} \mathrm{C}$ which is likely to be due to cold crystallisation; it is reported that crystallisation of PLA happens at $80-100{ }^{\circ} \mathrm{C}$. But, the lower Tg of PLA over hybrid composite may be due to the plasticisation of the polylactic acid by the supercritical fluid. The area under $\tan \delta$ verses temperature curve decreased with fibre addition suggesting increase in the damping ability of hybrid fibre PLA composite compared to pristine PLA. Fibre reinforced PLA composites are sensitive to the thermal degradation.

The $\tan \delta$ verses temperature plot represent the molecular transition and the $\tan \delta$ peak shows the Tg which is also around $68^{\circ} \mathrm{C}$ and not much difference could be noticed between PLA and hybrid composites. Generally at room temperature there is an increment in the storage modulus and improved with fibres addition. Decrease in storage modulus was recorded with increase in temperature which indicate the softening of composites at $60^{\circ} \mathrm{C}$ in which the loss modulus was increased Figure 7(a, b).

\subsubsection{DSC and TGA}

Result from DSC and TGA of hybrid green composites are shown in Figure 8(a, b). It is revealed that an endothermic peak exists near Tg may be due to the physical ageing of the polymeric materials and exothermic peak under heating might have resulted because of 
changes in molecular structure or non-equilibrium condition. The re-crystallisation peak indicates the restructuring of certain crystalline structures at high temperature. The neat PLA specimen showed glass transition $\left(\mathrm{T}_{\mathrm{g}}\right)$ at about $60^{\circ} \mathrm{C}$ and melting peak $\left(\mathrm{T}_{\mathrm{m}}\right)$ at about $175{ }^{\circ} \mathrm{C}$. Natural fibre PLA composites are known to be sensitive to heat absorption and thermally degrade which leads to changes in the molecular structure. Addition of hybrid natural fibre greatly influenced the crystallinity of the composites which is accomplished by other researches to ${ }^{[60,73]}$ Further, addition of hybrid fibre enhanced the elongation and impact properties where in the starch content in the hybrid fibre might have acted as plasticizer and thus enhanced the thermal stability and reduced the brittle behaviour of PLA composite.

\subsection{XRD Analysis}

Crystallinity of green composites made with reinforcement of hybrid fibre studied using X-ray diffractometer is shown in Figure 9. It is evident from the results that the degree of crystallinity increased with hybrid fibre addition. Addition of hybrid natural fibre might have influenced the melt viscosity and induced strain hardening leading to increased crystallinity of the composites. Manufacturing of the hybrid composites using sisal and hemp fibre with polylactide was energy saving process since, composites were made under low temperature and pressure and resulted in dimensional stability along with the less molecular degradation.

\subsection{SEM Microstructure of Composites}

Morphological images (SEM micrographs) of fracture surfaces of biodegradable hybrid composites specimens are shown in Figure 10. It appears that there was reasonably good interfacial adhesion among the fibre and PLA and a moderate dispersion of fibre could be seen. However, some fibre pull-out was noticed in the fractured specimens, wherein sisal fibre which was mostly in bundle form was found to have de-bonded more than the hemp fibre (Figure $10 \mathrm{~A}$ ). It is observed that the average cells size in PLA found to be larger than that of hybrid fibre PLA composites which may be due to the nucleation in the presence of fibre leading to reduction in the cell size. Earlier work done using pull-out tests 
showed that PLA flax fibre composites had poor adhesion between fibre and matrix when the flax fibres were in the single fibre form(Islam et al., 2010).

It is apparent from the SEM microstructure that the non-linear deformation behaviour in the composites indicates plastic deformation and micro-crack initiation at the fibre matrix interphase leading to crack propagation along the fibre boundary (Figure 10 B, C). Moreover, there is evidence of there being few voids and good interfacial bonding giving only limited fibre pull-out resulting in enhanced mechanical properties This is an improvement on earlier work on PLA composites with incorporation of agricultural residues where there was non-uniform adhesion between fibre and PLA, more porosity and insignificant improvement in the mechanical properties. Hence, it is apparent from the present study that synthesis and operating conditions of processing equipment are also an important factor besides addition of plasticizer/compatibliser for surface modification and interfacial adhesion.

\subsection{Density and Water Absorption of Composites}

Lower density of natural fibre over synthetic fibre is their advantageous property. Table 2 shows the physical and mechanical properties of hybrid natural fibre PLA composites fabricated under extrusion and injection moulding system. In the present study, the density of hybrid composites was $1.2 \mathrm{~g} / \mathrm{cm}^{3}$. Natural fibre density varied from $1.3-1.5 \mathrm{~g} / \mathrm{cm}^{3}$, however, measured density of hemp fibre and sisal fibre varied from $1.2-1.48 \mathrm{~g} / \mathrm{cm}^{3}$ which is about $43 \%$ lower than the density of E-glass $\left(2.6 \mathrm{~g} / \mathrm{cm}^{3}\right)$. Neat PLA showed about 1.25 $\mathrm{g} / \mathrm{cm}^{3}$ density. Application of such low density composites not only may result in saving fuel in automotive applications but also introduce fully biodegradable composites for the environmental friendly and sustainable growth. For water absorption study five injection moulded impact specimens were used. The submerged test specimens in distilled water were taken out periodically and subsequently weighed, after wiping out the water on the specimen surface. Water absorption of hybrid fibre PLA composites showed 1.08 \pm 0.21\% which is found to be very less than that of timber products 


\section{Use of biodegradable composite materials and their environmental consequences}

Biodegradable thermoplastic polymer composites have many advantages over thermoset polymer composites, metals and glass. Most plastics are produced from non-renewable petroleum products. Though some of the plastics are being recycled, most of them are nonrecyclable and lead to environmental contamination due to land filling and improper disposal. In the present study PLA, a thermoplastic polyester derived from corn starch, was used as an ideal binding medium, which is 100\% biodegradable, about 8 times recyclable and compostable at the end of its service life and is a promising and sustainable materials leading to reduction in the societal solid waste disposal problem. These biodegradable materials have great scope for use in packaging, electronics, windmill blades, agricultural, medical and use in automotive parts such as door trim panels and transmission covers: Ford Motor Company has already introduced wheat straw /polypropylene based composites in the 2010 Ford Flex. Bio plastics are being developed and used in making utensils in fast food service centres and food packaging. From this experimental programme, mechanical properties, water absorption studies, thermal analysis and crystallinity and microstructure properties showed that high performance biodegradable hybrid fibre reinforced composite can be made using sisal and hemp fibre together with polylactic acid using extrusion (melt processing) and injection moulding. The developed hybrid composite materials can be used in automobile applications, especially the interior parts including back safety cover, door panels. Application of these hybrid biodegradable composite materials will reduce the persistent plastic waste and leading to maintaining balanced $\mathrm{CO}_{2}$ level/ emission in the atmosphere.

\section{Concluding remarks}

The present study demonstrated fabrication of fully biodegradable hybrid green composites combining hemp and sisal fibre with polylactic acid using extrusion and injection moulding and assessed their properties for the possible automotive application. During synthesis of PLA composites, incorporation of fibre showed good compatibility during processing. Biodegradable hybrid green composites have resulted in good material properties in terms of tensile strength $(46.25 \pm 6.75 \mathrm{MPa})$, Young's modulus $(6.1 \pm 0.58 \mathrm{GPa})$, flexural 
strength (94.83 $\pm 11.21 \mathrm{MPa})$, low density $(1.14 \pm 0.075)$ and low water absorption (1.06 $\pm 0.18 \%)$. The developed hybrid composite exhibits good dimensional stability, low molecular degradation and thermal resistance. The SEM microstructure revealed the improved interfacial adhesion between PLA matrix and fibre with hybridisation of natural fibre resulting in enhanced mechanical and thermal properties of composites. It is apparent that bending strength and modulus are much higher than that tensile strength. The improvement in the mechanical properties of hybrid fibre composite is largely governed by properties of sisal and hemp fibres together with the intrinsic interfacial characteristics of matrix. The outcome of the present study demonstrates the hybridisation of natural fibre having different properties in making fully biodegradable composites and their performance for possible advanced applications including use in computers, lap top, electronic goods, food packaging and bio-medical purposes. These hybrid biodegradable composite are renewable and avoid the dependence of diminishing fossil resources.

\section{Acknowledgements}

This work was carried out with the funding by the Council of Scientific and Industrial Research (CSIR), Government of India under the award of Sir CV. Raman Fellowship. Authors are thankful to CSIR India and Prof. Janis Swan, the University of Waikato for the support provided to perform research work at the University of Waikato, New Zealand.

\section{References}

Bleuze, L., Lashermes, G., Alavoine, G., Recous, S., Chabbert, B., 2018. Tracking the dynamics of hemp dew retting under controlled environmental conditions. Ind. Crops Prod. 123, 55-63. https://doi.org/10.1016/j.indcrop.2018.06.054

Bodros, E., Pillin, I., Montrelay, N., Baley, C., 2007. Could biopolymers reinforced by randomly scattered flax fibre be used in structural applications? Compos. Sci. Technol. 67, 462-470. https://doi.org/10.1016/j.compscitech.2006.08.024

de Oliveira, F., da Silva, C.G., Ramos, L.A., Frollini, E., 2017. Phenolic and lignosulfonate-based matrices reinforced with untreated and lignosulfonate-treated 
sisal fibers. Ind. Crops Prod. 96, 30-41. https://doi.org/10.1016/j.indcrop.2016.11.027

Dubey, S.P., Thakur, V.K., Krishnaswamy, S., Abhyankar, H.A., Marchante, V., Brighton, J.L., 2017. Progress in environmental-friendly polymer nanocomposite material from PLA: Synthesis, processing and applications. Vacuum 146, 655-663. https://doi.org/10.1016/j.vacuum.2017.07.009

Gan, I., Chow, W.S., 2018. Antimicrobial poly(lactic acid)/cellulose bionanocomposite for food packaging application: A review. Food Packag. Shelf Life 17, 150-161. https://doi.org/10.1016/j.fpsl.2018.06.012

Goudenhooft, C., Bourmaud, A., Baley, C., 2018. Conventional or greenhouse cultivation of flax: What influence on the number and quality of flax fibers? Ind. Crops Prod. 123, 111-117. https://doi.org/10.1016/j.indcrop.2018.06.066

Islam, M.S., Pickering, K.L., Foreman, N.J., 2010. Influence of alkali treatment on the interfacial and physico-mechanical properties of industrial hemp fibre reinforced polylactic acid composites. Compos. Part Appl. Sci. Manuf. 41, 596-603. https://doi.org/10.1016/j.compositesa.2010.01.006

Kaschuk, J.J., Frollini, E., 2018. Effects of average molar weight, crystallinity, and hemicelluloses content on the enzymatic hydrolysis of sisal pulp, filter paper, and microcrystalline cellulose. Ind. Crops Prod. 115, 280-289. https://doi.org/10.1016/j.indcrop.2018.02.011

Liu, M., Thygesen, A., Summerscales, J., Meyer, A.S., 2017. Targeted pre-treatment of hemp bast fibres for optimal performance in biocomposite materials: A review. Ind. Crops Prod. 108, 660-683. https://doi.org/10.1016/j.indcrop.2017.07.027

Miculescu, F., Maidaniuc, A., Voicu, S.I., Thakur, V.K., Stan, G.E., Ciocan, L.T., 2017. Progress in Hydroxyapatite-Starch Based Sustainable Biomaterials for Biomedical Bone Substitution Applications. ACS Sustain. Chem. Eng. 5, 8491-8512. https://doi.org/10.1021/acssuschemeng.7b02314

Ochoa, M., Collazos, N., Le, T., Subramaniam, R., Sanders, M., Singh, R.P., Depan, D., 2017. Nanocellulose-PE-b-PEG copolymer nanohybrid shish-kebab structure via interfacial crystallization. Carbohydr. Polym. 159, 116-124. https://doi.org/10.1016/j.carbpol.2016.12.028 
Panaitescu, D.M., Frone, A.N., Chiulan, I., 2016. Nanostructured biocomposites from aliphatic polyesters and bacterial cellulose. Ind. Crops Prod. 93, 251-266. https://doi.org/10.1016/j.indcrop.2016.02.038

Pappu, A., Patil, V., Jain, S., Mahindrakar, A., Haque, R., Thakur, V.K., 2015. Advances in industrial prospective of cellulosic macromolecules enriched banana biofibre resources: A review. Int. J. Biol. Macromol. 79, 449-458. https://doi.org/10.1016/j.ijbiomac.2015.05.013

Pappu, A., Saxena, M., Thakur, V.K., Sharma, A., Haque, R., 2016. Facile extraction, processing and characterization of biorenewable sisal fibers for multifunctional applications. J. Macromol. Sci. Part A 53, 424-432. https://doi.org/10.1080/10601325.2016.1176443

Pappu, A., Thakur, V.K., 2017. Towards sustainable micro and nano composites from fly ash and natural fibers for multifunctional applications. Vacuum 146, 375-385. https://doi.org/10.1016/j.vacuum.2017.05.026

Pickering, K.L., Efendy, M.G.A., Le, T.M., 2016. A review of recent developments in natural fibre composites and their mechanical performance. Compos. Part Appl. Sci. Manuf., Special Issue on Biocomposites 83, 98-112. https://doi.org/10.1016/j.compositesa.2015.08.038

Requile, S., Goudenhooft, C., Bourmaud, A., Le Duigou, A., Baley, C., 2018. Exploring the link between flexural behaviour of hemp and flax stems and fibre stiffness. Ind. Crops Prod. 113, 179-186. https://doi.org/10.1016/j.indcrop.2018.01.035

Saradava, B.J., Kathwadia, A.J., Gorviyala, A.D., Joshi, V.K., 2016. Mechanical Characterization of Hemp Fiber Reinforced Polyester Composites: A Review. J. Polym. Compos. 4, 1-3.

Sarasini, E., Fiore, V., 2018. A systematic literature review on less common natural fibres and their biocomposites. J. Clean. Prod. 195, 240-267. https://doi.org/10.1016/j.jclepro.2018.05.197

Saxena, M., Morchhale, R.K., Asokan, P., Prasad, B.K., 2008. Plant fiber - Industrial waste reinforced polymer composites as a potential wood substitute material. J. Compos. Mater. 42, 367-384. https://doi.org/10.1177/0021998307087014 
Senthilkumar, K., Saba, N., Rajini, N., Chandrasekar, M., Jawaid, M., Siengchin, S., Alotman, O.Y., 2018. Mechanical properties evaluation of sisal fibre reinforced polymer composites: A review. Constr. Build. Mater. 174, 713-729. https://doi.org/10.1016/j.conbuildmat.2018.04.143

Singha, A.S., Kumar Thakur, V., 2008. Saccaharum Cilliare Fiber Reinforced Polymer Composites [WWW Document]. J. Chem. https://doi.org/10.1155/2008/941627

Singha, A.S., Shama, A., Thakur, V.K., 2008. X-Ray Diffraction, Morphological, and Thermal Studies on Methylmethacrylate Graft Copolymerized Saccharum ciliare Fiber. Int. J. Polym. Anal. Charact. 13, 447-462. https://doi.org/10.1080/10236660802399747

Singha, A.S., Thakur, V.K., 2009. Fabrication and Characterization of H. sabdariffa FiberReinforced Green Polymer Composites. Polym.-Plast. Technol. Eng. 48, 482-487. https://doi.org/10.1080/03602550902725498

Thakur, M.K., Gupta, R.K., Thakur, V.K., 2014. Surface modification of cellulose using silane coupling agent. Carbohydr. Polym. 111, 849-855. https://doi.org/10.1016/j.carbpol.2014.05.041

Thakur, V.K., Singha, A.S., 2010. Mechanical and Water Absorption Properties of Natural Fibers/Polymer Biocomposites. Polym.-Plast. Technol. Eng. 49, 694-700. https://doi.org/10.1080/03602551003682067

Thakur, V.K., Singha, A.S., Thakur, M.K., 2012. Biopolymers Based Green Composites: Mechanical, Thermal and Physico-chemical Characterization. J. Polym. Environ. 20, 412-421. https://doi.org/10.1007/s10924-011-0389-y

Thakur, V.K., Thakur, M.K., 2014. Processing and characterization of natural cellulose fibers/thermoset polymer composites. Carbohydr. Polym. 109, 102-117.

Zhang, Y., Li, Y., Thakur, V.K., Gao, Z., Gu, J., Kessler, M.R., 2018a. High-performance thermosets with tailored properties derived from methacrylated eugenol and epoxybased vinyl ester. Polym. Int. 67, 544-549. https://doi.org/10.1002/pi.5542

Zhang, Y., Thakur, V.K., Li, Y., Garrison, T.F., Gao, Z., Gu, J., Kessler, M.R., 2018b. Soybean-Oil-Based Thermosetting Resins with Methacrylated Vanillyl Alcohol as Bio-Based, Low-Viscosity Comonomer. Macromol. Mater. Eng. 303, 1700278. https://doi.org/10.1002/mame.201700278 